\title{
Percepción sociolingüística de los peruanos residentes en Chile acerca de su variedad del español en interacción con el español chileno
}

\author{
Valeria Pozo* \\ Pontificia Universidad Católica de Chile
}

\begin{abstract}
Resumen
El presente estudio da cuenta de la percepción sociolingüística que tienen los peruanos residentes en Chile - de la comuna de Santiagorespecto a su variedad del español en contacto con la chilena. Para recoger los datos se aplicó una encuesta directa a 30 personas que cumplieran con los requisitos de haber nacido en tierras incaicas, llevar al menos un lustro de residencia en Chile y ser mayor de 18 años de edad. Dentro de los hallazgos obtenidos se reveló que, según los encuestados, sociolingüísticamente existe una situación paradójica por parte de los peruanos, pues, mientras consideraban que los chilenos valoraban más su variedad del español, antes que la local, y hacían de la suya la más prestigiosa, se sentían empero disminuidos socialmente al recibir malos tratos y discriminación por parte de ellos. Es en consecuencia de esto, que los peruanos trataran de aproximarse al español chileno, dejando de lado su propia variedad, con el fin de pasar desapercibidos y encajar en la sociedad en la que ahora residen.
\end{abstract}

\footnotetext{
* Para correspondencia, dirigirse a: Valeria Pozo P. (vgpozo@uc.cl), Veintiuno de Mayo
} 024, La Cisterna, CP 7990447, Santiago, Chile. 
Palabras clave: percepción sociolingüística, español peruano, español chileno, variedades lingüísticas en contacto.

\title{
Sociolinguistic perception of Peruvians living in Chile about THEIR VARIETY IN INTERACTION WITH CHILEAN SPANISH
}

\begin{abstract}
This study will reveal the sociolinguistic perception that Peruvians living in Santiago de Chile have regarding their own dialect of Spanish in contact with the Chilean dialect. To collect the data, a direct survey was applied on 30 people that met the requirements of being born in Peru, having at least five years of residence in Chile and being over 18 years old. Among the findings that were obtained it was revealed that, according to survey respondents, there is a paradoxical sociolinguistic situation: while Chileans considered valuable the Peruvian variety of Spanish, making it more prestigious than the local dialect, Peruvians feel socially diminished when receiving mistreatment and discrimination by Chileans. Therefore, Peruvians try to accomodate to Chilean Spanish and they leave aside their own variety, in order to go unnoticed and fit in the Chilean society.
\end{abstract}

Keywords: sociolinguistic perception, Peruvian Spanish, Chilean Spanish, language varieties in contact.

Recibido: 15/07/14 Aceptado: 20/10/14

\section{INTRODUCCIÓN}

El estudio de percepciones sociolingüísticas se torna necesario para comprender cómo los hablantes de una determinada comunidad lingüística ocupan la lengua en su uso social y en los contextos en los que interactúan. Así también, en cómo actúan frente a la variación lingüística de la que son portadores y al cambio lingüístico al que se exponen en su comunicación con el otro, describiendo de qué forma perciben estos las lenguas que conocen y utilizan para su desarrollo diario (Moreno Fernández 2012:18).

A pesar de su importancia en el ámbito de nuestra lengua hispana, investigaciones a nivel internacional que abarquen este tipo de temática son aún escasas. Sin embargo, poco a poco ha ido cobrando auge esta área 
de la lingüística, pues en la actualidad es posible hallar algunos estudios que han abordado tangencialmente el tema. Como Caravedo (2009) en Italia, quien examina el rol de la percepción como proceso cognoscitivo central en el estudio de la migración, durante el proceso de adquisición de la variación lingüística de la lengua local, como también de la adaptación del individuo/grupo en la sociedad receptora. Castillo y otros autores (2010) en Venezuela, investigan acerca de la percepción que possen una cierta cantidad de hablantes ante una determinada expresión de uso frecuente al interior de sus fronteras. En España, Siqués et al. (2008) observaron cuál era la percepción que poseían niños inmigrantes en la comunidad de Cataluña en relación con el aprendizaje de la lengua catalana como segunda lengua, entre otros.

En el caso de Chile, una de las investigaciones que más se han acercado al tema de percepción es la de Rojas (2012), quien se enfoca netamente en la percepción y valoración que tienen los hablantes de la capital chilena con respecto a la variación geográfica del español a lo largo de todo el país en tres dimensiones valorativas: similitud, calidad, y agrado en diferentes situaciones y contextos. También destaca la investigación, dentro esta misma área, de Oteíza (2007), quien se interioriza por analizar qué percepciones lingüísticas tiene un grupo de hablantes bilingües universitarios que vive en Estados Unidos, cuya lengua materna/heredada es el español y no el inglés.

Como se dijo anteriormente, pese a que este tema ha encontrado un incipiente espacio dentro de nuestra sociedad, se cree que aún es escaso, por lo que se pretende, sea por medio de esta investigación en conjunto con otras, no solo ampliar un nuevo nicho investigativo acerca de cuál es la percepción que tienen los peruanos residentes en Chile respecto a su variedad peruana, sino también indagar qué opinan de la chilena y qué prejuicios tienen del contacto que surge entre ambas en tierras en que ellos no figuran ser los locales.

\section{MARCO CONCEPTUAL}

Halliday plantea que estudiar el contexto en estudios lingüísticos es fundamental porque ayuda a comprender la elección que prefieren los hablantes al momento de interactuar con otros en una situación determinada (1978: 213). Gee, por su parte, define contexto como "un amplio conjunto de factores que acompañan al lenguaje en uso" (2004: 29), por lo que debiera 
hablarse de "contextos de uso". Estos incluirían el ambiente material, la gente presente (lo que saben y creen), el lenguaje que viene antes y después del enunciado, las relaciones sociales de la gente involucrada, su etnicidad, género, identidades sexuales, culturales, históricas, y los factores institucionales a los que están supeditados. Por lo tanto, si la comunicación y la lengua son, en esencia, sustento y producto de las relaciones interindividuales de un contexto determinado, es necesario explicitar, desde esta área de investigación, los factores extralingüísticos que inciden en el uso de la lengua, como: la variación y el cambio lingüístico, la acomodación y la elección de una lengua por sobre otra, así como también, las implicaciones y consecuencias lingüísticas en ciertas organizaciones y contextos sociales.

Caravedo, desde la concepción de Labov, dice que el espacio sociolingüístico solo se remite a particularidades geográficas más que a localizaciones de variantes lingüísticas (2003: 51). No obstante, ella cree que los hablantes tienen una percepción más amplia del espacio -sea de tipo suprarregional, nacional o incluso transnacional- que la variante diatópica reconocida por el otrora lingüista de la variación. Es decir, para Caravedo el espacio configura un universo que contempla los aspectos psicosociales de los individuos centrales y sus interacciones con otros grupos dentro y fuera de la localidad de residencia, por lo que estos no estarían sujetos a un suelo en específico, sino más bien sería algo trasladable en función del movimiento que los hablantes hagan por sí mismos: "los individuos desarrollan en general una percepción muy refinada de lo propio y de lo ajeno que los hace inmediatamente diferenciable, incluso para el hablante común que no es de ese lugar" (2004: 1122). Es decir, en esa nueva localidad no solo se ha ubicado el hablante físicamente, sino que, de forma inherente, ha trasladado su cultura, sus tradiciones. No obstante, Caravedo agrega que dentro de la definición de "espacio", existe una dimensión de tipo social más que meramente geográfico y una de tipo simbólico-cognoscitivo frente a lo que se consideraba netamente como objetivo. El contenido social daría cuenta del carácter colectivo del lenguaje, mientras que contenido simbólicocognoscitivo haría referencia a cómo el propio hablante conceptualiza el espacio en el que se inserta, confiriéndole un significado sentimental al lugar al que pertenece. Es decir, todo hablante, sea cual fuere su origen, tiene como referencia el propio espacio social, que con contenidos laxos o específicos, da sentido a aquello que considera como "propio" y mantiene la diferencia con hablantes de distinta procedencia.

Aquella distinción que se establece entre uno y otro grupo constituye, según Moreno Fernández, lo que se denomina "comunidad de habla", dado que se conforma por un conjunto de hablantes que comparten al menos una misma lengua (2009: 23). Lo que los haría fácilmente reconocibles 
entre sí, pues se rigen bajo normas y códigos de aceptación y segregación de similar naturaleza, en la que juzgan y tipifican a los emisores de otras variedades según sus actitudes y percepciones lingüísticas (Labov 1990: 73; cf. Blas Arroyo 2008: 109). Por lo tanto, se habla de dialectos en contacto cuando dos o más dialectos de una misma lengua convergen en un espacio lingüístico determinado. De esas situaciones surgen entonces fenómenos lingüísticos que afectan a todos los niveles de la lengua, divididos en tres grupos: los primeros tratan la interferencia, convergencia, préstamo léxico y calco lingüístico, que en la lengua se presentan tras el acercamiento con otra de diferentes características; los segundos, se refieren al uso de varias lenguas, a la elección de una lengua específica, a la sustitución de una lengua por sobre otra, y a la alternancia de lenguas que suelen darse en contextos bilingües; el tercero, en cambio, relata las variedades derivadas del contacto de lenguas y del surgimiento de otras nuevas como: las lenguas pidgin, las lenguas criollas y lenguas medias, que conocidas también como de frontera o transición, se caracterizan por el colinde que existe entre dos o más idiomas que están cercanos geográficamente.

En consecuencia con ello, cabe aclarar que en una sociedad en la que dos o más lenguas conviven, suelen presentarse situaciones de indecisión de uso de una lengua que está por sobre la otra, como ocupar la de menor uso solo para situaciones específicas o bien, derogar su uso totalmente. Esta elección de lengua, según Herman, depende de tres situaciones psicológicas a las que se expone el hablante confundido (Herman 1983:186; cf. Moreno Fernández 2009: 235). La primera está relacionada con las necesidades propias del hablante, la segunda estaría sujeta a la actividad en la que se desenvuelve ese hablante, y, la tercera, a las características del grupo social del que proceda ese individuo. Sin embargo, hay que tener en consideración que existen ciertas comunidades con dialectos en contacto, que demuestran una resistencia por mantener la lengua de origen frente a la que es predominante. Esta lealtad lingüística, como se le ha denominado, ha estado presente en ciertos contextos en defensa y supervivencia de la lengua materna que está próxima a expirar. Por el contrario, existe también lo que se ha denominado deslealtad lingüistica, referida cuando los hablantes, gobernados por un sentimiento de vergüenza y desarraigo cultural, reniegan de su lengua de origen con la finalidad de integrarse a la comunidad que ahora los recibe.

Blas Arroyo, por su parte, ha determinado esta conducta como la actitud lingüística que posee el hablante ante ciertas situaciones, es decir, "las posturas críticas y valorativas que los hablantes realizan sobre fenómenos específicos de una lengua" (2008: 322), entendido también como aquello que piensan los hablantes sobre las mismas, o bien sobre sus variedades dialectales o sociolectales con los que se comunica. En palabras de López 
Morales, es "el estado de disposición" que tiene un hablante, quien actúa de manera específica ante un estímulo dado (2004: 277). Sin embargo, las actitudes lingüísticas tienen que ver no solo con lo que a las lenguas se refiere, sino que también con la identidad de los grupos que las manejan. Puesto que existe una relación entre lengua e identidad, esta última ha de manifestarse en las actitudes de los individuos hacia esas lenguas y sus usuarios.

Según Moreno Fernández, la identidad es entendida como aquello que permite diferenciar a un grupo de otro, configurado por medio de dos instancias: la primera de forma objetiva, se caracteriza por las instituciones que la componen y las costumbres culturales que practican; y, la segunda, de manera subjetiva, configura la idea de diferenciación de sus miembros respecto de los demás usuarios con los que conviven (2009: 143). Por lo tanto cuando se determina qué uso es más prestigioso que otro es en acuerdo con la apreciación subjetiva de la comunidad de habla que lo protagoniza. Este prestigio, considerado una actitud, es según el mismo autor, "una concesión de estima y respeto hacia individuos o grupos que reúnen ciertas características y que lleva a la imitación de las conductas o creencias de esos individuos o grupos" (1990: 187), que desde la perspectiva de los usuarios, será lo que él cree es lo correcto y lo que considere más prestigioso, pues sin caer en usos prescriptivos, se rige por un uso más estilístico, dentro de lo aceptable que considera para sí.

Con respecto a lo anterior, vale decir que uno de los pilares donde se cimentan las bases de la actitud lingüística es la conciencia sociolingüistica, la cual condiciona la manera de actuar que se tiene frente a un determinado estímulo o situación sociolingüística (2009: 177). Es decir, el hablante, ante ciertos hechos que le afectan o conciernen, establece un patrón de conducta que le hace discernir entre aquello que está bien y aquello que no lo está en absoluto. Por ejemplo, los hablantes saben cuáles son los usos lingüísticos que su comunidad de habla prefiere y cuál rechaza, por lo que estos tienen la posibilidad de escoger qué uso es más apropiado ante una determinada ocasión y cuáles son los que podrían afectar sus intereses. En relación a ello, una de las consecuencias directas que subyace de esto es la seguridad y la inseguridad lingüistica. La primera se presenta cuando el uso del hablante coincide con lo que él considera correcto o adecuado. La segunda, en cambio, surge cuando el uso no concuerda con la actitud de aceptación o rechazo dejando aparecer la dubitación en el hablante de no saber actuar ante una determinada situación a la que se enfrenta.

Todo esto estaría condicionado, según Caravedo, a la percepción lingüística, pues es este el mecanismo cognoscitivo esencial en el proceso de adquisición/aprendizaje lingüístico, que permite tanto la captación sensorial como conceptual de una lengua (2009: 24). Moreno Fernández, por su parte, 
dice que la percepción es la respuesta valorativa que se obtiene después de recibir un mensaje -o un estímulo cualquiera-, bajo los criterios que la cultura y la comunidad de habla han impuesto para categorizar aquello como "bueno" o "malo" (2009: 184). En este sentido, el autor reconoce tres planos diferentes en los que se halla la percepción: el primero hace referencia a la realidad social a la que pertenece el hablante; el segundo, a las variaciones lingüísticas de las que es protagonista; $y$, el tercero, al contacto lingüístico al que se expone de manera constante (2012). En definitiva, son los entornos socioculturales aquellos que otorgarían los valores a la lengua y que de acuerdo con la norma establecida por ellos mismos, serán "aceptados" o "rechazados" dependiendo del grado de proximidad o alejamiento que tengan con la comunidad de habla, y de lo relevante que sea para la configuración identitaria del grupo.

Con respecto a las variedades de español a que se hace alusión más arriba, cabe decir que existen, en la actualidad, unas que poseen más prestigio que otras, dependiendo de quien haga referencia de ellas. Para no crear confusión y evitar los juicios subjetivos de la lengua, se ha ideado la "Teoría prototípica" de la lengua española, en la que se establecen diferentes categorías mentales relacionadas con sus variedades dialectales (López 1997: 193; cf. Moreno Fernández 2012: 244), dividida en tres niveles: en el nivel básico, en el que se encuentran los diferentes tipos de español que se reconocen en el continente americano, están por ejemplo, el "chileno", "peruano", "argentino"; mientras que en el segundo, en el nivel superodinado, se encontrarían categorías más generales, compuestas por subcategorías que presentan características similares como su ubicación espacial, por ejemplo: el español "boliviano" y el "peruano", que generalizado bajo un mismo rótulo estarían bajo la clasificación de "español andino"; y, en un tercer nivel, está el subordinado, que se categoriza por las variedades de acuerdo con su localidad geográfica, como el español "santiaguino", "mendocino" o "madrileño", que con una homogeneidad relativa dentro de su país, se diferenciarían unos de otros de una manera muy tenue. 


\section{METODOLOGÍA}

\subsection{SUJETOS DE LA MUESTRA}

Para analizar la percepción sociolingüística que tiene parte de la comunidad peruana en la comuna de Santiago, se encuestó, de forma azarosa, a 30 individuos en el centro de Santiago. Ellos, empero, debían cumplir con tres requisitos: haber nacido en tierras incaicas, residir al menos 5 años en Chile y ser mayores de 18 años de edad. Esto se consideró para establecer, principalmente, diferencias sociológicas y lingüísticas entre el lugar de origen y la comunidad receptora, así como también para que el encuestado evidenciara los cambios que ha ido adquiriendo y abandonando en un tiempo significativamente largo alejado del terruño. Se cree, además, que la mayoría de edad es una edad pertinente para discernir las posibles similitudes y diferencias que existen o podrían presentarse en ambas variedades lingüísticas. Cabe destacar que se escogió la comuna de Santiago para realizar este estudio, por ser ella la que concentra la más alta tasa de inmigrantes en el país, sobre todo los de origen peruano (Hidalgo y Torres 2009: 309).

Dado el carácter exploratorio de nuestro estudio, no se asignó una representatividad proporcional demográfica del país, sino más bien se analizó un pequeño porcentaje de ella que sirviera de piloto a posibles proyectos futuros.

\subsection{INSTRUMENTO DE LA RECOLECCIÓN DE DATOS}

Para medir la percepción lingüística que tenían los hablantes de origen peruano en contacto con la variedad chilena en Santiago de Chile se utilizó el método directo (Moreno Fernández 1990). Este método consiste en preguntar cara a cara, de encuestador a encuestado, acerca de cuáles son las preferencias, opiniones y percepciones de habla de ellos mismos en tierras que no son las natales. Para la recolección de esos datos se utilizó de instrumento una encuesta de diecinueve preguntas, dividida en dos partes. La primera parte de dicho instrumento consiste en una ficha personal del encuestado, en la que se indagan datos como cuál es su sexo, qué edad tiene, cuántos años lleva en Chile, cuál es su ocupación y qué nivel de instrucción alcanzó, de manera que entregue una visión panorámica acerca de cuál es su realidad socioeconómica y cultural con la que se desenvuelve en el centro de la capital. Cabe destacar que las preguntas de esta sección contienen 
respuestas cerradas que van entre dos y nueve alternativas, dependiendo de la información que se desea recabar.

La segunda parte, en cambio, contiene catorce preguntas acerca de cómo perciben los encuestados su habla de origen en contacto con la local. Las primeras tres preguntas de esta sección sirven para romper el hielo, empatizar con el encuestado y reunir información acerca de cuáles fueron los principales motivos que lo incitaron venir a Chile, así como también si se siente cómodo vivir en nuestro país y si Santiago es distinto a su lugar de procedencia, de manera que el encuestado sienta confianza y conteste con la máxima sinceridad posible. Luego, las preguntas que van desde la 4 a la 12 consisten netamente en el objeto de estudio de percepción sociolingüística. En esta parte de la encuesta, por medio de preguntas cerradas, los encuestados elicitan opiniones acerca de su habla peruana en Santiago con respecto al lugar del que provienen como también en su interacción con la chilena, pasando revista si se han sentido discriminados por ser peruanos y si consideran que su variante del español se ha transformado a través de los años en que han permanecido fuera de sus fronteras. Casi todas estas preguntas se presentan con solo dos alternativas de manera de hacer más precisa la información que se está recopilando. Finalmente, las dos últimas preguntas, 13 y 14, son de tipo abierta, no obligatorias, en la que los encuestados tienen la posibilidad de desarrollar argumentos que complementen la información antes dada y en la que se intenta dar cuenta del porqué de sus respuestas anteriores.

En cuanto a lo que a la toma de muestra se refiere, esta fue aplicada en las medianías del casco histórico del centro de Santiago en el perímetro que va de norte a sur y poniente a oriente entre las calles San Pablo a Catedral, y Bandera a Veintiuno de mayo, respectivamente. La selección de las personas, que contestaría la encuesta se realizó en forma azarosa a gente que iba deambulando libremente por lugares públicos, como también a gente que se encontraba en su lugar de trabajo. Cabe destacar en tanto que previo a la toma de muestra fue necesario validar el instrumento con cinco personas ${ }^{1}$. Se les tomó la encuesta como si fueran parte del estudio para ver si presentaba errores como ambigüedad o imprecisión. Dado que no hubo problemas de ese y de ningún tipo se procedió a seguir con los pasos posteriores.

La toma de muestra se realizó en alrededor de seis horas de un día viernes del mes de julio de 2013. Cada encuesta realizada en forma individual demoró aproximadamente quince minutos en promedio por persona. Vale decir, esta

\footnotetext{
1 Los resultados vertidos en la toma de muestra piloto no fueron considerados dentro de los resultados totales de este estudio.
} 
interacción fue siempre mediada por el encuestador, quien, tomando nota de las respuestas del encuestado, reproducía de manera textual al papel las respuestas cerradas y abiertas que el encuestado vertía, sin tomar posición alguna sobre lo que estaba escuchando.

Quienes cumplían el rol de exploradoras de la investigación y, en consecuencia, encargadas de recabar la información que se necesitaba para este estudio, respondían al perfil de dos mujeres estudiantes de cuarto año de la Licenciatura en Letras Hispánicas, que con formación consistente en el área de lingüística, podían comprender la finalidad de este estudio y transmitirla a los diferentes encuestados sin apreciaciones de ningún tipo, sino más bien, que su resultado enriqueciera un campo de la sociolingüística que no ha sido abordado recientemente. Para ello se les hizo una breve capacitación acerca de qué se quería recopilar con la encuesta, a quiénes había que acudir, qué requisitos debían cumplir los encuestados y cómo y dónde debía aplicarse el instrumento.

\subsection{Procedimiento de ANÁlisis}

Las respuestas suministradas por cada integrante que participó en la muestra fue procesada en una plantilla de datos en Excel, en la que se concentraron todas las contestaciones registradas anteriormente por las exploradoras. Luego, en dicha matriz se tabularon los datos obtenidos y se sacaron los porcentajes de cada categoría que, organizados en tablas, evidenciaron de manera más clara y precisa, las tendencias que predominaban, en aquel entonces, en una parte de la comunidad peruana acerca de su variedad lingüística en el corazón de Santiago.

\section{ANÁLISIS}

$\mathrm{Al}$ procesar los resultados totales obtenidos en cada una de las preguntas de la encuesta se evidencian porcentajes que reflejan diferentes situaciones acerca de cómo se sienten los peruanos en Chile, cómo miran ellos nuestra variedad de habla y si creen que esta variedad se ha mezclado con la que ellos portaban desde su tierra de origen. 


\subsection{PRESENTACIÓN Y DISCUSIÓN DE LOS RESULTADOS}

4.1.1. Rasgos sociológicos: Traslado, recepción de la comunidad inmigrante $y$ diferencias entre culturas

Tabla 1. Motivación de trasladarse a Chile

\begin{tabular}{|c|c|}
\hline \multicolumn{2}{|c|}{$\begin{array}{l}\text { 1. Usted hace años que ya reside en Chile, } \\
\text { ¿cuál fue el principal motivo de su traslado? }\end{array}$} \\
\hline a) Económico & $63 \%$ \\
\hline b) Político & $0 \%$ \\
\hline c) Tenía a mi familia aquí & $30 \%$ \\
\hline d) Porque me gusta Chile & $7 \%$ \\
\hline
\end{tabular}

Esta parte de la encuesta refiere a la percepción sociológica que tienen los hablantes, pues se comienza por preguntar cuál fue la principal motivación que gatilló el éxodo de su tierra natal hacia Chile. De un total de 30 encuestados, un $63 \%$ dijo que lo había hecho por motivos económicos, pues necesitaban de trabajo para su supervivencia; mientras que un $30 \%$ dijo haberse venido por su familia, pues en turbas migratorias anteriores se habían desplazado a estas tierras en busca de un mejor porvenir; y solo un $7 \%$ dijo que lo había hecho porque le gustaba nuestro país. No obstante, nadie afirmó que su estadía se debiera a motivos políticos, como exilio, amenazas de muerte, entre otros.

Tabla 2. Recepción y diferencias con el lugar de origen

\begin{tabular}{|l|l|}
\hline \multicolumn{2}{|l|}{ 2. ¿Se siente cómodo en Chile? } \\
\hline a) Sí & $87 \%$ \\
\hline b) No & $13 \%$ \\
\hline $\begin{array}{l}\text { 3. ¿Considera que Santiago es distinto a su lugar de } \\
\text { origen? }\end{array}$ \\
\hline a) Sí & $90 \%$ \\
\hline b) No & $10 \%$ \\
\hline
\end{tabular}

Luego, cuando se pregunta acerca de si se siente cómodo en nuestro país, sea el motivo que fuere por el que se vino, la respuesta de la mayoría fue que sí lo estaba, lo que representa al $87 \%$ de la población estudiada, frente a un $13 \%$ 
que dijo no estarlo. Posteriormente, cuando se les pregunta si considera que Santiago es distinto al lugar de donde proviene, un $90 \%$ respondió que sí lo era, mientras que solo tres personas $(10 \%)$ dijeron no considerar diferencia alguna entre el lugar del cual emigraron con la capital chilena.

\subsubsection{Percepción sociolingüistica: cómo perciben los peruanos su variedad del español en contacto con la chilena en el centro de Santiago}

Tabla 3. Percepción sociolingüística del español peruano en interacción con el chileno

\begin{tabular}{|l|l|}
\hline \multicolumn{2}{|l|}{$\begin{array}{l}\text { ¿Considera que en Santiago se habla distinto a su lugar } \\
\text { de origen? }\end{array}$} \\
\hline a) Sí & $83 \%$ \\
\hline b) No & $17 \%$ \\
\hline $\begin{array}{l}\text { 1. Con respecto a su habla peruana en Chile iconsidera } \\
\text { que aún es distinta a la que utilizan los chilenos? }\end{array}$ \\
\hline a) No & $90 \%$ \\
\hline b) Sí & $10 \%$ \\
\hline $\begin{array}{l}\text { 2. ¿Qué español prefiere, el hablado en Perú o el hablado } \\
\text { en Santiago de Chile? }\end{array}$ \\
\hline a) Español hablado en Perú & $87 \%$ \\
\hline b) Español hablado en Santiago de Chile & $13 \%$ \\
\hline
\end{tabular}

En la pregunta 4 se puede observar que los peruanos perciben el habla chilena como una variedad distinta a la peruana, puesto que el $83 \%$ de los encuestados respondió considerarla diferente a la de su lugar de origen, frente a un $17 \%$ que dijo no hallar diferencia entre ambas localidades. Por lo que se infiere que gran parte de la población estudiada percibe y está consciente de que entre el habla chilena y la peruana existen diferencias lingüísticas reconocibles al oído andino.

En la pregunta 5, el 90\% de los peruanos dijo no considerar su habla peruana diferente a la que se habla en Chile, frente a un 10\% que sí dijo reconocer hablar distinto a los locales. La percepción de similitud de la variedad peruana al habla chilena, de parte de los encuestados, podría deberse al largo tiempo que llevan viviendo en nuestro país, entre cinco años o más, con lo que se demuestra que ellos han adquirido nuestra variedad debido al constante roce al que se enfrentan a diario. Cabe destacar en tanto, que estas cifras no solo muestran que los peruanos residentes en nuestro país 
se consideran de una comunidad idiosincrática diferente, sino que además se identifican con una comunidad de habla distinta a la que aquí se utiliza, pese a que ambas culturas, tanto la chilena como la peruana, comparten el mismo idioma.

En la pregunta 6 se puede evidenciar, de acuerdo con los porcentajes entregados, que cuando se le pregunta a los representantes del pueblo inca acerca de qué español prefieren: el de Perú o el hablado en Chile, un $87 \%$ contesta preferir el hablado en el país vecino, mientras que solo un $13 \%$ dice preferir el hablado aquí. Por lo que queda de manifiesto que los residentes peruanos demuestran una lealtad lingüística con su lugar de procedencia, pues pese a no figurar como los naturales de esta tierra, aún mantienen un vínculo de cercanía e identidad con su variedad materna.

Tabla 4. Percepción sociológica basada en la experiencia

\begin{tabular}{|l|c|}
\hline \multicolumn{2}{|c|}{ ¿Usted se ha sentido alguna vez discriminado por ser peruano? } \\
\hline a) Sí & $40 \%$ \\
\hline b) No & $60 \%$ \\
\hline \multicolumn{2}{|c|}{ ¿Considera que el español peruano es valorado en nuestro país? } \\
\hline a) Sí & $90 \%$ \\
\hline b) No & $10 \%$ \\
\hline
\end{tabular}

Desde un punto de vista más sociológico, se les preguntó a los encuestados si en su condición de inmigrante peruano han percibido diferencias en el trato hacia ellos, al punto de sentirse discriminados por parte de la población chilena por el hecho de haber nacido en tierras andinas. La tabla 4 muestra que el $60 \%$ de los encuestados dijo no haberlo sentido nunca, frente a un $40 \%$ restante, que dijo sí haberse sentido discriminado alguna vez. Por lo que se infiere que a partir de las respuestas de quienes dijeron no haberse sentido discriminados nunca por el hecho de ser peruanos, podría ser producto de que se consideran ya parte de la sociedad chilena con igualdad de derechos y parte de su comunidad de habla también sin que ellos lo manifiesten abiertamente. Por lo que comienza a vislumbrarse una asimilación con la cultura local y un desprendimiento inconsciente de la cultura de origen, sin que los mismos protagonistas lo perciban de manera tal.

Sin embargo, pese a los resultados anteriores en que los encuestados manifiestan sentirse discriminados al interior de las fronteras chilenas, se muestra que solo tres personas $(10 \%)$ consideraron que su variedad del 
español no era valorada en Chile, frente a un $90 \%$ que dijo percibir que su español peruano sí lo era. En consecuencia, se cree que existe una situación paradójica en la percepción sociolingüística de los peruanos en su relación con los chilenos, pues mientras algunos creen ser discriminados por su lugar de origen y otros dicen no sentirlo, lo cierto es que sí perciben una aceptación de su variedad de habla pese a ser peruana. Por lo que se considera existiría una valoración de tipo lingüística al pueblo peruano, de parte del chileno, que avalaría aún más la apreciación que tienen los andinos de su variedad del español frente a la local. En consecuencia, de acuerdo con estas cifras, podría determinarse que los chilenos concederían un cierto prestigio lingüístico a la variedad peruana, puesto que así lo perciben sus protagonistas.

Tabla 5. Identificación en la variedad

\begin{tabular}{|l|c|}
\hline \multicolumn{2}{|l|}{$\begin{array}{l}\text { 9. Cuando usted está hablando con chilenos, en el centro } \\
\text { de la ciudad de Santiago, cree que habla como: }\end{array}$} \\
\hline a) Peruano & $23 \%$ \\
\hline b) Chileno & $17 \%$ \\
\hline c) Peruano-chileno & $60 \%$ \\
\hline $\begin{array}{l}\text { 10. Desde su experiencia, el habla peruana en contacto } \\
\text { con la chilena ¿sufre transformaciones? }\end{array}$ \\
\hline a) Sí & $70 \%$ \\
\hline b) No & $30 \%$ \\
\hline $\begin{array}{l}\text { 11. ¿Cree que estas transformaciones son positivas o } \\
\text { negativas? }\end{array}$ \\
\hline a) Positivas & $68 \%$ \\
\hline b) Negativas & $32 \%$ \\
\hline $\begin{array}{l}\text { 12. Considera usted que existe algún tipo de expresión } \\
\text { o chilenismo que lo haga sentir mal por el hecho de ser } \\
\text { peruano }\end{array}$ \\
\hline a) Sí & $50 \%$ \\
\hline b) No & $50 \%$ \\
\hline
\end{tabular}

Al plantear a los encuestados (la pregunta 9) acerca de cómo era su habla cuando se comunicaban con chilenos en el centro de la capital, un $60 \%$ de ellos contestó que lo hacía como peruano-chileno, un $23 \%$ como peruano y el $17 \%$ como chileno. Por lo que se evidencia la aparición de un híbrido lingüístico, entre la variedad peruana y chilena, puesto que los encuestados 
reconocen hablar con elementos de ambas culturas. Fenómeno que se entiende, según Moreno Fernández (2009), como transculturación, ya que los participantes de esta encuesta no se identifican ni con la cultura de origen ni con la de la sociedad que les ha dado acogida. En el caso de los peruanos, el hecho de residir y convivir con chilenos todo el tiempo ha hecho que su español adquiera vocablos que son típicos de esta zona, adoptándolos a su vocabulario y utilizándolos inconscientemente sin distinción de habla alguna. Este hecho lleva poco a poco a la asimilación de la comunidad receptora y por ende al desprendimiento de la cultura de origen, replicándose en respuestas en las que ya dicen estar sintiéndose peruano-chilenos como también en las que admitían, abiertamente, estar hablando ya como un chileno más dentro de esta cultura.

Posteriormente, dado el gran tiempo que llevan los encuestados en Chile, al menos cinco años, se procedió a preguntarles, en base a su experiencia, si consideraban que su habla peruana había sufrido transformaciones al estar en permanente contacto con la local en tierras chilenas. Tal como lo muestra la tabla 5, en la pregunta 10 , un $70 \%$ de los encuestados dice sí haber percibido estas transformaciones, mientras que solo un $30 \%$ asegura no haberlo sentido así. Los resultados que representan a las 19 personas que respondieron afirmativamente reflejan que reconocen en su variante del español un rasgo propio que los identifica como peruanos, demostrando una arraigada lealtad lingüística que se resiste a los posibles cambios; frente a otros, que dijeron sí percibir modificaciones en su habla, sea por una deslealtad lingüística inconsciente o premeditada, o bien, producto del constante roce con chilenos que hace inevitable la adopción de algunos "chilenismos". No obstante, existe la posibilidad también de que quienes respondieron en forma negativa, lo hayan hecho debido a que no logran distinguir ambas variedades lingüísticas, puesto que ambas provienen de la misma cuna idiomática, el español.

La pregunta 11 muestra de qué tipo es la transformación lingüística, positiva o negativa, que dicen percibir los peruanos cuando hallan cambios en su variedad del español. Un $68 \%$ de los encuestados dice percibir aquellas transformaciones de forma positiva, frente a un $32 \%$ que dice creer que son negativas. De igual modo que la pregunta anterior, quienes aprecien estas transformaciones positivamente estarán aceptando poco a poco los modismos y expresiones propias del habla chilena en su variedad, en señal de que están asimilándose a la cultura en la cual residen, pues pareciera ser ese el medio de entrada a la cultura local que los identificaría como uno más de ellos.

En cambio en la pregunta 12, tal como lo muestra la tabla 5, se presentó una paridad en sus respuestas al preguntar a los encuestados si consideraban que existía alguna expresión o chilenismo que los hiciera sentir mal por el hecho de ser peruano. Frente a este contexto, un 50\% afirmaba que sí las 
había, frente a la otra mitad que afirmaba no percibir ninguna. En el caso de aquellos quienes consideraron que sí había expresiones que les causaran daño, de índole xenófobas, se cree que es porque mantienen aún un lazo identitario con la cultura de origen y cualquier tipo de agresión a ella les ofende. Los otros, en cambio, el no percibirlos puede deberse a dos razones: que no prestan mayor atención a los dichos peyorativos a los que se exponen a diario, porque no les interesa lo que digan los demás y se evitan todo tipo de enfrentamientos, o bien es porque se han desprendido ya de los rasgos de su cultura de origen, impidiéndoles reconocer cualquier insulto hacia la misma.

\subsubsection{Percepción sociolingüistica: qué expresiones o chilenismos les afecta emocionalmente por su condición de peruano e inmigrante}

De la pregunta anterior se desprende una pregunta abierta de carácter voluntario que al igual que todas las anteriores solo fue respondida por la mitad de los encuestados. Es decir, solo quince personas de treinta dicen reconocer expresiones, emitidas por los chilenos, que les afectan emocionalmente. Esta no voluntad de responder esta parte de la encuesta, más que al desinterés, se especula que se debe porque afecta el lado emocional de los encuestados. Por un lado, podría ocasionarles ira al rememorar malos recuerdos, o bien, pena por los tratos crueles de los que han sido víctima por su condición de inmigrantes.

Tabla 6. Expresiones y/o chilenismos que molestan a los peruanos encuestados

\begin{tabular}{|l|c|c|}
\hline Expresión & $\begin{array}{l}\mathbf{N}^{\circ} \text { de personas que dijo le } \\
\text { molestaba esa expresión }\end{array}$ & Porcentaje \% \\
\hline Peruano/a culia'o/a & 8 & $53,3 \%$ \\
\hline $\begin{array}{l}\text { Peruano/a tenía } \\
\text { que ser }\end{array}$ & 2 & $13,3 \%$ \\
\hline Cholo/a & 2 & $13,3 \%$ \\
\hline $\begin{array}{l}\text { Come ratas/ } \\
\text { come palomas }\end{array}$ & 2 & $13,3 \%$ \\
\hline Pé & 1 & $6,7 \%$ \\
\hline TOTAL: & 15 & $99,9 \%$ \\
\hline
\end{tabular}

La mayoría de quienes respondieron esta pregunta, con un 53,3\% de la población, coincidieron en que la expresión "peruano culia'o" les molestaba emocionalmente porque los menospreciaba por su origen incaico. Seguidamente aparecieron expresiones como "peruano/a tenía que ser", 
"cholo/a" y "comerratas/comepalomas", representando al 13,3\%, con dos personas cada una. Finalmente, solo una persona, representando al 6,7\%, dijo sentirse estigmatizado por los chilenos al usar el pe -en alusión a la variante de pues característica de los peruanos y caricaturizada por muchos- como muletilla típica del pueblo andino.

Las respuestas recabadas en esta encuesta muestran que, pese a percibirse prestigiosos lingüísticamente, los peruanos residentes en Chile se sienten disminuidos por los miembros de la cultura local, puesto que los agreden verbalmente con expresiones peyorativas que los estigmatizan socialmente. Esto se observa en el hecho de que la mitad de los encuestados coincidió en una misma respuesta sin mediación alguna de parte de las encuestadoras que condicionara sus respuestas. Es decir, cada respuesta fue dada de manera espontánea, por lo que se concibe existe una conducta constante en los chilenos que discrimina y estigmatiza a los del país vecino por su condición de inmigrante-peruano. Lo que quedaría demostrado con expresiones xenófobas y descalificadoras emitidas por los chilenos, en la que ellos figurarían como los superiores por ser dueños de las tierras, o bien, porque hay un pasado histórico-político en el que ellos se perfilan como los vencedores, entre otras diferencias.

Ahora bien, cuando se les pregunta a los peruanos acerca de por qué las expresiones, antes dichas, les causan incomodidad, muchos de ellos dicen que en el caso de "peruano culia'o" es porque se sienten inferiores a los chilenos, puesto que la consideran una expresión agresiva. En el caso de "peruano/a tenía que ser" y la muletilla pe, piensan que son expresiones xenófobas que los discriminan por el hecho de ser de origen incaico, en el que creen socialmente no estar en igualdad de condiciones frente a un chileno cualquiera. En cuanto a la expresión "cholo/a", los peruanos perciben que es una discriminación de tipo racial que los juzga por su color de piel, pese a que en Chile también se encuentra ese tono cutáneo. No obstante, parecieran aceptarla, puesto que consideran que por ser ellos los foráneos tienen menor derecho a opinar, permitiéndoles a los chilenos que los agredan verbalmente por su apariencia física como por otras características que los perfile como peruanos. Este hecho hace vislumbrar que no solo se sientan disminuidos socialmente, pese a ser más prestigiosos lingüísticamente, sino que además renieguen de su identidad cultural, provocándoles inseguridad lingüística al momento de comunicarse con chilenos. Finalmente, ante la expresión "comerratas" o "comepalomas" sostienen que es una locución sumamente peyorativa que los hace sentir inferiores y estigmatizados por el hecho de concentrarse en un lugar poblado por palomas, como la Plaza de Armas o la Catedral; o bien, por pertenecer a un grupo estigmatizado de "pobre" al que solo le alcanzaría para comer ratas dada su abundancia en los suburbios, 
donde ellos residen, como también por ser quienes con más frecuencia se presentan en las zonas carentes de la ciudad; y, por ser gratuitas y estar al alcance de cualquier condición económica, incluso la de ellos, "los pobres".

\section{CONCLUSIONES}

$\mathrm{Al}$ término de este estudio se puede concluir que los peruanos encuestados muestran preferir más su español peruano por sobre el chileno, así como también dicen percibir un aprecio, por parte de estos últimos, en el uso de su variedad lingüística. Este aprecio y apego por su variedad idiomática podría deberse a la herencia cultural que se vivió durante la época colonial americana, en las localidades cercanas al virreinato limeño (de Granda 1994: 62). Esta institución, como entidad territorial de la Corona española en América, se convirtió en la principal sede receptora de nobles y letrados oriundos de la Península, que con su acento y dominio de la lengua concedieron prestigio a esta variedad lingüística heredada hasta nuestro días (Quesada 2002). En este sentido, los resultados son coherentes con el prestigio que dicen reconocer los andinos a su variedad del español frente al español chileno, así como también una cierta lealtad lingüística cuando reconocen estar a favor de su variedad materna en lugar de sustituirla por la que rige a los santiaguinos. Sin embargo, ocurre una situación dicotómica cuando se les pregunta acerca de cómo perciben ellos su habla cuando lo hacen con los chilenos, puesto que la mayoría responde que lo hace como peruano-chileno. Ante esta situación, se evidencia en los encuestados una cierta inseguridad lingüística en el uso de su variedad materna, ya que se observa un relativo abandono de ella, producto de una asimilación cultural que ha ido ocurriendo de manera inconsciente que solo algunos perciben, $o$ bien, porque la lengua pareciera ser la puerta de entrada que les permitiría insertarse al modelo que predomina. En palabras de Caravedo, la lengua es el objeto central en la supervivencia y en la integración social del individuo que comparte con otros (2009), por lo que determinaría como algo "natural" la conducta que están teniendo los peruanos, de desprenderse de su variedad natal para adquirir la local, en función de insertarse sin prejuicios en la sociedad que les da acogida y en la que ahora residen.

Por lo tanto, pese a que la valoración idiomática que adquiere el español peruano en nuestro país está por sobre la chilena, otorgándole mayor prestigio, no cobra real importancia en la práctica puesto que se ha comprobado, a través de las respuestas vertidas en esta encuesta, que son 
otros los factores de tipo extralingüístico los que afectan la percepción que tienen de sí mismos, en este caso es el desprestigio social el que condiciona el actuar del pueblo peruano a abandonar aquello que le es admirable al chileno, su variedad de lengua. Es decir, los peruanos al confirmar que se están sintiendo chilenos o peruanos-chilenos cuando los locales hablan con ellos, retrata la tendencia al transnacionalismo e hibridez identitaria que los gobierna en ese momento, la misma que desembocará en el futuro en un desprendimiento total de la identidad natal. El porqué de esta situación cobra sentido cuando los peruanos reconocen haber sido discriminados, o afectados emocionalmente por expresiones y/o "chilenismos", de índole xenófobas, utilizada por los chilenos en ataque racial hacia los foráneos. Por lo que se cree que acrecienta en ellos el deseo de pertenecer aún más a la sociedad chilena, sin rasgos lingüísticos que los perfilen como de origen incaico, para no tener diferencias de ningún tipo. Ahora bien, hay que tener en cuenta que dentro de la situación de "extranjero" que cobran los peruanos al emigrar a tierras chilenas, estos ponen en funcionamiento una percepción de tipo social, hasta cierto punto desmesurada, que implica asociar su modo de hablar diferente al de ellos con la finalidad de insertarse a la comunidad que los acoge y pasar desapercibidos sin ninguna "etiqueta"que delate su origen.

Para comprender de mejor manera la situación del español peruano frente a su prejuicio social, se ha de tener en cuenta que, dentro del imaginario colectivo de los chilenos, la inmigración peruana para ellos representa un estigma social reconocible por todos. Pues, tal como lo describe Stefoni (2002), su grupo social encarna lo que los chilenos denominan "actividades no calificadas", es decir, ocupación de poco prestigio social dado el bajo nivel de instrucción que se necesita para practicarla y la despreciable remuneración que se recibe una vez realizada, como por ejemplo, la labor del obrero y la de asesora del hogar, íconos de la pobreza que estigmatizan no solo su bajo nivel de ingreso sino la precariedad en la que se insertan (Schiappacase 2008). Esto justificaría la desvaloración social que persiste en el inconsciente colectivo del pueblo chileno hacia la comunidad peruana, pues son los miembros de estos últimos los que están dispuestos, en su mayoría, a ejercer cargos de este tipo, dada su alta oferta laboral y casi nula capacitación para poder ejercerla, como también por la alta cantidad de vacantes que no han ocupado los chilenos, al no querer desempeñarse en ese tipo de cargos producto del estigma que eso representa.

Por último, se concluye que a pesar de que el español peruano se perfila con más prestigio que el español chileno, los andinos estarían dispuestos a acomodar sus propias pautas de conducta lingüística mediadas por la conciencia, con el fin de acomodarse al grupo de la comunidad chilena y ser identificados como parte de ella (Moreno Fernández 2009). Estos resultados se justificarían entonces con la siguiente premisa de Caravedo: 
“aprehender el sistema de variación de la lengua en el país receptor resulta crucial en el desarrollo del proceso de adaptación del individuo/grupo en la nueva sociedad" (2009: 37).

\section{REFERENCIAS BIBLIOGRÁFICAS}

Blas Arroyo, José Luis. 2008. Sociolingüística del español: desarrollo y perspectiva en el estudio de la lengua española en contexto social. Madrid: Cátedra.

Caravedo, Rocío. 2003. Principios del cambio lingüístico. Una contribución sincrónica a la lingüística histórica. Revista de Filología Española 83: 39-62.

2004. El espacio en la linguística de la variación. En Rosa M. Castañer y José M. Enguita (coords.). In memorian Manuel Alvar (1923-2001), pp. 1119-1129. Zaragoza: Institución "Fernando el Católico".

2009. La percepción selectiva en situación de migración desde un enfoque cognoscitivo. Lengua y Migración 2: 21-38.

Castillo, Luis, Cruz Colmenares, Carolina Rojas y José Romero. 2010. Percepción lingüística del hablante en cuanto al uso de la expresión "dale pues". Boletín de Lingüística 34: 5-24.

De Granda, Germán.1994. Formación y evolución del español de América. Época colonial. En Español de América, español de África y hablas criollas hispánicas. Cambios, contactos $y$ contextos, pp. 49-92. Madrid: Gredos.

GeE, James. 2004. What makes it critical? En Rebecca Rogers (ed.). An introduction to Critical Discourse Analysis in Education, pp. 19-50. Mahwah: Lawrence Erlbaum Associates.

HallidaY, M. A. K. 1978. Languaje as a social semiotic. The social interpretation of language and meaning. Londres: Edward Arnold.

Hidalgo, Rodrigo y Alma Torres. 2009. Los peruanos en Santiago de Chile: transformaciones urbanas y percepción de los inmigrantes. Polis 22:307-326.

López Morales, Humberto. 2004. Sociolingüística. Madrid : Gredos.

Moreno Fernández, Francisco. 1990. Metodología sociolingüística. Madrid: Gredos.

2009. Principios de sociolingüística y sociología del lenguaje. Barcelona: Planeta. 2012. Sociolingüistica cognitiva. Preposiciones, escolios y debates. Madrid: Iberoamericana.

Oteíza, Teresa. 2007. Percepciones lingüísticas de hablantes bilingües: análisis evaluativo. Estudios Filológicos 42: 155-173.

Quesada, Miguel Ángel. 2002. El español de América. 2. ${ }^{a}$ ed. Cartago: Editorial Tecnológica de Costa Rica.

RoJAS, DARío. 2012. Percepción y valoración de variedades geográficas del español de Chile entre hispanohablantes santiaguinos. Boletín de Filología 47 (1): 137-163.

Schiappacase, Paulina. 2008. Segregación residencial y nichos étnicos de los inmigrantes internacionales en el área Metropolitana de Santiago. Revista Norte Grande 39: 21-38.

Siqués, Carina, Ignasi Vila y Santiago Perera. 2008. Percepciones y actitudes del alumnado extranjero y del profesorado: un estudio empírico en las aulas de acogida de Cataluña. Electronic Journal Research Psychology 7: 103-132.

Stefoni, Carolina. 2002. Inmigración peruana en Chile: una oportunidad a la integración. Santiago: Universitaria. 